\title{
Relationship between sickness absence and length of service
}

\author{
S. J. POCOCK ${ }^{1}$ \\ TUC Centenary Institute of Occupational Health, London School of Hygiene and Tropical \\ Medicine, London WC1
}

\begin{abstract}
Pocock, S. J. (1973). Brit. J. industr. Med., 30, 64-70. Relationship between sickness absence and length of service. A longitudinal study of 454 new employees in one factory showed that sickness absence rates in the first six months of service were less than half the rates during the next four and a half years. This is presumed to be partially caused by the lack of company sick pay during this initial period. A cross-sectional study of 1263 men in employment in 1964 showed that men with long service (e.g., over 10 years) are less frequently absent than the rest whereas days lost was not associated with length of service. This is thought to relate to the increased job satisfaction and greater responsibility of long-service employees. It is also shown that an employee's sickness absence experience in the first year of employment can be used as an indicator of future absence liability. However, it is more reliable in the prediction of the 'frequently sick' than the 'severely sick' employee. Previous studies of the effect of length of service on sickness absence are also discussed.
\end{abstract}

Previous investigations into the effect of length of service on the employee's sickness absence have been somewhat inconsistent in their conclusions, largely due to the limitations of the methods used (see the review of the literature below). The methods described in this investigation have been designed to overcome the difficulties encountered by others but have nevertheless remained fairly straightforward.

First, a longitudinal study is described, the sickness absence experience of employees in one organization being followed over a five-year period starting on their first day of employment. Using the same data an assessment is also made of the extent to which an individual employee's future sickness absence experience can be predicted from his record in the first year of employment in the organization. This is followed by a cross-sectional study, the relationship between the individual's length of service

${ }^{1}$ Present address: Statistical Laboratory, State University of New York at Buffalo, 4230 Ridge Lea Road, Amherst, N.Y. 14226, U.S.A. and one year's sickness absence being established after allowance has been made for associations with age and hours of work. Finally, the interpretation of the results is discussed.

\section{Literature}

The simplest and most obvious approach to the study of absenteesim in relation to length of service is to take a cross-section of employees in a company, divide them into strata according to their length of service, and see if those with short or long service have more or less absence in a year than the rest of the sample. The main flaw in this method is that length of service is often related to other factors such as age, older employees usually having longer service. Thus any simple association found between sickness absence and length of service may be wholly attributable to the effects of such factors and this may account for the contradictory conclusions of Hazard (1951) and Wyatt (1945).

One method of eliminating such effects is to use 
standardization techniques as illustrated in the crosssectional analysis described below. Froggatt (1970), in a study of one- and two-day absences, used regression analysis instead, but such assumptions of a linear relationship might be inappropriate. One further restriction in the use of cross-sectional methods is that any associations found may be due to selection criteria rather than any causal relationship. For example, the type of employee taken on may vary from year to year depending on company policy and the state of the labour market.

The use of a longitudinal approach eliminates any effect of initial selection. Cooper and Payne (1965) undertook such an investigation in three Merseyside factories following employees' sickness absence over periods of 16 or more years. Such groups of 'stayers' are not representative of all employees and also it is difficult to assess whether any trends are due to age and length of service or other factors such as increased sick-pay or changes in certification requirements. These problems and also the relatively small sample sizes may account for the inconsistency found in their results.

A more informative use of longitudinal analysis was made by Hill and Trist (1955). They studied men who joined one factory in a particular year and who stayed for the next four calendar years and observed the frequency of absence in the eight sixmonthly periods contained in these four years. They showed that the overall absence frequency declined as the men's length of service increased, with the exception of the low frequency in the first six months, but that 'sanctioned absence' which consisted mostly of sickness absence showed a steady increase in frequency. They suggest that as the employee increases his length of service there is a natural progression from unsanctioned to sanctioned forms of absence but they fail to consider whether this could be explained by increases in sick-pay or other benefits provided for long-service employees. Another restriction is imposed by the use of exact calendar years for the recording of absence rather than observing each employee from his first day of employment. For instance, at the start of the first six-month period employees have a range of 0 to 11 months' completed service in the company and this makes it impossible to evaluate absence frequency in the first six months of service.

Buzzard and Shaw (1952) and Denerley (1952) have both shown that the introduction of a company sick pay scheme caused an increase in sickness absence. The fact that new employees are often ineligible for such schemes must be taken into account as it is liable to affect their attitude towards sickness absence.

The use of longitudinal methods is perhaps most valuable in assessing the development of absence behaviour in the first few years of service but to study men with longer periods of service a cross-sectional approach may be more appropriate.

\section{A longitudinal study}

The data used throughout this study relate to the sickness absence records of male manual workers at one site of a large continuous process industry in southeast England. In this section the 454 men who joined the company at some time during 1955-59 and were still employed at the start of 1965 form the study population. Analysis is based on their sickness absence experience in the first five years of employment.

Throughout this paper sickness absence includes all spells of absence from work due to medical incapacity lasting one shift or more. Until mid-1965 all manual workers on the site required a medical certificate for all such spells. Since then self-certification has been in operation for short spells and has resulted in a marked change in absence behaviour. To avoid any resultant complications, all absence in this paper relates to the period up to 1965. The seasonal pattern of recruitment for this population of new employees was not very marked except for a slight reduction during the winter months, and therefore seasonal variations are unlikely to affect the trends in sickness absence obtained from observing employees from their date of joining. The fact that their dates of joining are spread over a five-year period is an advantage because the observed trends cannot be unduly affected by annual fluctuations in the incidence of respiratory infection. At the end of 1964 only $31 \%$ of this population were aged 40 or more and $24 \%$ were under 30 . Approximately half the men were on continuous three-shift work.

In Fig. 1 the pattern of sickness absence frequency

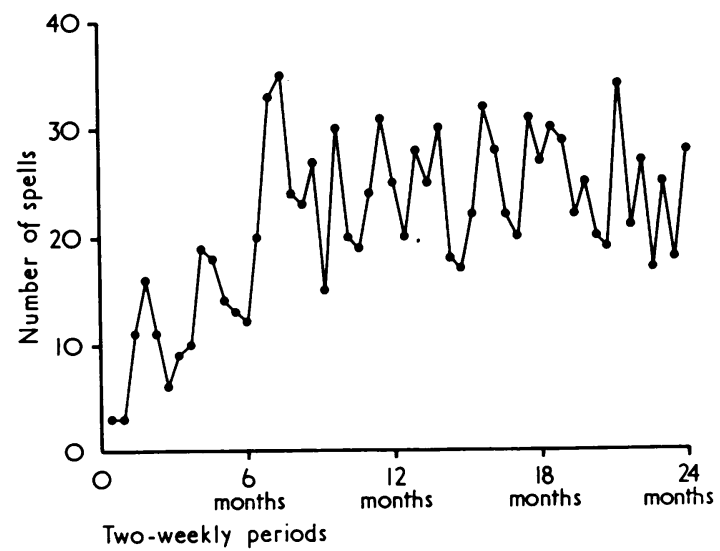

FIG. 1. The first two years of service. Sickness absence frequency in two-weekly periods from date of joining for 454 men. 
during the first two years of service is shown by a graph of the numbers of spells occurring in twoweekly periods as measured from the dates of joining of the $\mathbf{4 5 4}$ men. The most striking observation is that the number of spells occurring in the first six months of service is below the level achieved during the subsequent 18 months and, in particular, sickness absence is almost non-existent in the first four weeks of service. This lack of sickness absence in the first six months is most apparent in Fig. 2 which shows the frequency of sickness absence in the 10 six-monthly periods during the first five years of service. In fact the overall number of spells in the first six months was only $45 \%$ of the average number for the next nine periods of six months. Under the assumption of a Poisson distribution for such frequencies, this difference is significant at the $0 \cdot 1 \%$ level.

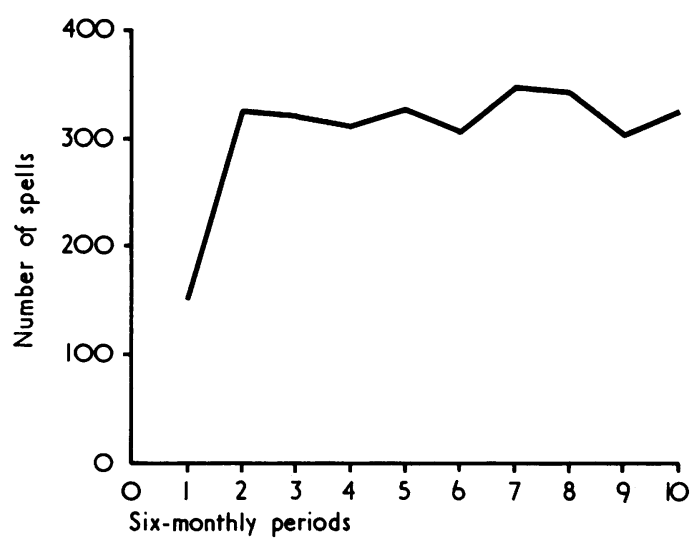

FIG. 2. The first five years of service. Sickness absence frequency in six-monthly periods from date of joining for 454 men.

In the company men do not receive any sick-pay for spells of sickness absence (except due to injury at work) until they have completed six months' service, and this would appear to be the most obvious explanation for the initial low level of sickness absence, especially in view of the sharp rise which occurs immediately afterwards (see Fig. 1). After six months' service, sick-pay consists of the full normal wage including shift allowance up to a maximum period depending on length of service followed by an equal period on half-pay.

The pre-employment medical examination may have resulted in men with severe chronic illness being refused employment. However, any subsequent development of chronic disease in new employees could not explain the trend in sickness absence as the great majority of spells are due to minor ailments and also the rise after six months was quite abrupt.

As regards variations in sickness absence frequency after the completion of six months' service, it can be seen from Fig. 2 that there is no evidence of any trend and the overall level remains remarkably constant. An analysis of the numbers of spells in each of the two-weekly periods contained in this four-and-a-half-year interval revealed the following results. This sequence of 117 values had a mean of 25.0 spells, variance equal to $24 \cdot 5$, and auto-correlation lag one equal to 0.04 . The closeness of the mean and variance and the small auto-correlation provide evidence to support the hypothesis that they relate to a sequence of independent Poisson random variables with constant mean. Thus it seems safe to conclude that annual and seasonal variations have had negligible effect on this sequence and furthermore it would appear that once the first six months of service are over, sickness absence frequency is not related to length of service in the first five years.

Having established a low incidence of sickness absence in the first six months of service, it is relevant to consider whether this lack of absence is: (i) more evident in some diagnoses than others; (ii) more evident in spells of short or long duration; (iii) more evident on certain days of the week.

By forming frequency distributions of spells of absence categorized by diagnosis (upper respiratory, digestive, injuries, organic nervous, musculo-skeletal, skin, bronchitis and other), duration (1 to 4, 5 to 13, 14 to 27 , and $28+$ days), and inception day (Monday to Friday, day-workers only), for both the first six months and the next four-and-a-half years of service, it was possible to compare the types of absence occurring in these two periods of service. None of the three contingency table tests had a $\chi^{2}$ value significant at the $5 \%$ level which leads to the conclusion that the low sickness absence rates did not relate to any particular diagnoses, durations or inception days of absence.

In Fig. 3 the severity of sickness absence (in calendar days) is shown for each of the 10 sixmonthly periods during the first five years of service for the same group of $\mathbf{4 5 4}$ men. The pattern is essentially the same as that already shown for the frequency of sickness absence except that there appears to be a further rise in absence severity during the fourth and fifth years of service. However, a study of long-term secular trends in sickness absence among more long-service men in employment since before 1955 until after 1964 showed that while the average spells per annum had remained relatively stable during 1955-64 the numbers of days of absence had risen appreciably during 1962-64. Therefore one is unable to conclude that the observed increase in absence severity is attributable to the increased length of service. 


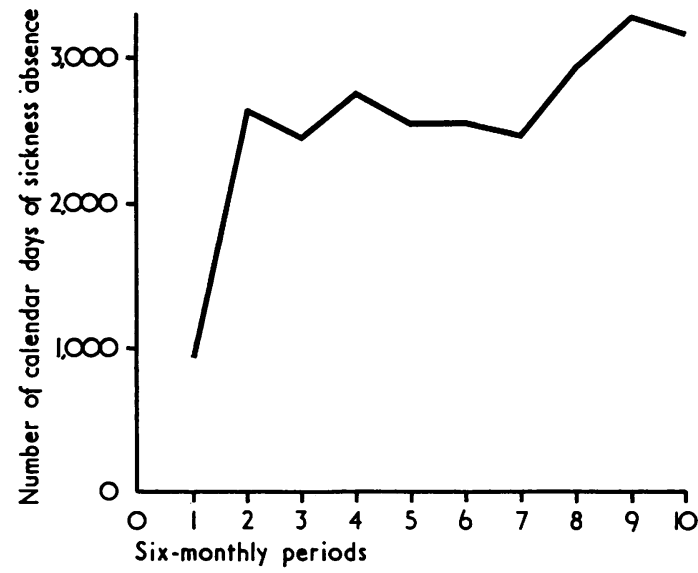

FIG. 3. The first five years of service. Sickness absence severity in six-monthly periods from date of joining for 454 men.

\section{Early assessment of sickness absence behaviour}

It has been shown in many organizations that the incidence of sickness absence is not distributed randomly in an industrial population (e.g., Newbold, 1927; Taylor, 1967). Arbous and Sichel (1954) developed a model of 'absence proneness' to explain this phenomenon. Though some of the assumptions of this model would appear to be incorrect (see Pocock, 1972) the fact remains that some employees have a greater liability to go off sick than others. In this section I describe the extent to which an employee's sickness absence experience in the first year of a new job can be used to assess his future absence liability. This is illustrated by the same population of 454 men who joined in the period 1955-59 and who stayed to the end of 1964.

First, the relationship of each employee's number of spells in the first year of employment to the number of spells he experiences in the next four years of service is considered. In Table 1 are shown the numbers of men with $0,1,2$, and 3 or more spells in the first year of service and the mean number of spells in the next four years for each of these four groups. From the very marked trend in these four mean values it would appear that men with a high frequency of sickness absence in the first year of service are liable to maintain this high frequency in subsequent years.

However, to determine the reliability with which one can use the first year's absence frequency as a guide to an employee's future absence frequency it is necessary to study the distributions of the frequency of sickness absence in the second to fifth years of service for each of the four groups of men shown in Table 1. Thus, in Fig. 4 are shown the percentages
TABLE 1

Distribution of Numbers of Spells in First Year of Service and Mean Numbers of Spells in NeXt Four Years for MEN IN EACH CATEgory

\begin{tabular}{c|c|c}
\hline $\begin{array}{c}\text { No. of spells } \\
\text { in 1st year }\end{array}$ & No. of men & $\begin{array}{c}\text { Mean spells/man in } \\
\text { 2nd to } 5 \text { th years }\end{array}$ \\
\hline 0 & 179 & $3 \cdot 87$ \\
1 & 163 & $5 \cdot 34$ \\
2 & 70 & $7 \cdot 36$ \\
3 or more & 42 & $11 \cdot 71$ \\
\hline Total & 454 & 5.66 \\
\hline
\end{tabular}

of employees with one or more, two or more, three or more, etc. spells of sickness absence in the second to fifth years of service for men classified into four groups according to their numbers of spells in the first year of service. It can be seen that these four distributions are quite different. For example, the percentages of employees with six or more spells in the second to fifth years of service are $25 \%, 41 \%$, $66 \%$, and $81 \%$ respectively for the groups with 0,1 , 2 , and 3 or more spells in the first year. The differences between these percentages are all significant at the $5 \%$ level except for that between the last two.

It is useful to consider how information of the sort presented in Fig. 4 can be of use to an employer who wishes to attempt to reduce sickness absence in his company. Out of the population of 454 new employees, $112(25 \%)$ had two or more spells of sickness absence in their first year of service. Also, a total of $119(26 \%)$ had eight or more spells in the

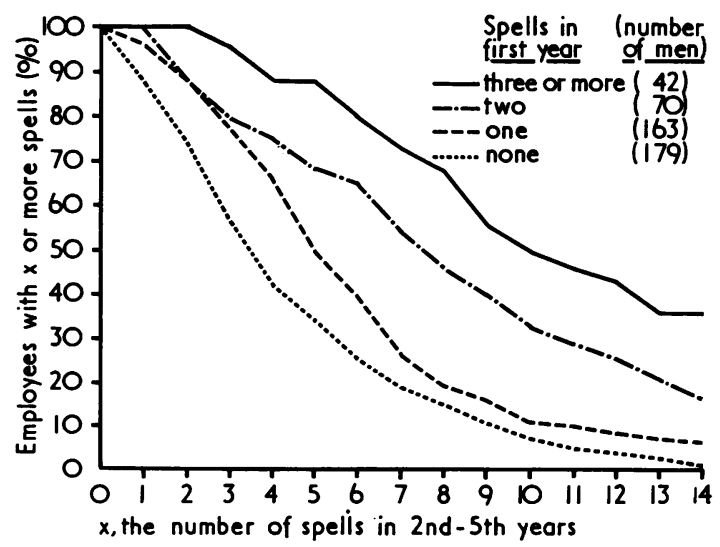

FIG. 4. Sickness absence frequency. Percentage of employees with 1 or more, 2 or more, 3 or more, etc. spells of sickness absence in the second to fifth years of service for men classified into four groups according to their numbers of spells in the first year of service. 
next four years. Now, $61(54 \%)$ out of this 'high frequency' group of 112 in the first year are also contained in the 'high frequency' group of 119 evaluated over the next four years. Suppose an employer attempted to reduce sickness absence by some means or other in a selected sample of employees. If such 'treatment' were applied at the end of the first year of employment to only a quarter of employees (i.e., those with two or more spells), over half of this 'treated' group would also have been in the 'top quarter' as regards absence frequency in the next four years. If absence prevention could be effective, its application to only a selected quarter of employees would therefore result in a considerable reduction in the overall frequency. For instance, the average frequency of sickness absence in the total population for the second to fifth years of service was 5.66 spells per man, but if the introduction of an absence prevention scheme, applied after a year to a selected quarter of new employees, could reduce their absence frequency to the level experienced by the rest of the population, the average spells per man in the second to fifth years would have fallen to 4.57 , a drop of $19 \%$.

As regards the severity of sickness absence (i.e., total days), the discrimination between 'high' and 'low' absence groups at the end of one year's service was somewhat poorer. Employees with no sickness absence in their first year were in general less likely to have much time off sick in the future. For instance, only $26 \%$ of these 179 first-year non-absentees had six weeks or more sickness absence in the next four years compared with $52 \%$ of the rest.

However, the actual amount of absence (spells or days) experienced by each of the 275 first-year absentees was not a useful indicator of their total days off sick in the next four years. 'For instance, the numbers of men with 1 to 6 days, 7 to 20 days, and 21 or more days sickness absence in their first year of employment were 101, 129, and 45 respectively. For these three groups the percentages with six or more weeks sickness absence in the next four years were $48 \%, 58 \%$, and $62 \%$, with no difference significant at the $5 \%$ level. Thus, there would appear to be more scope for predicting the 'frequently sick' rather than the 'severely sick' employee. This might be because the former is a behavioural characteristic whereas the latter is more related to genuine morbidity.

An alternative approach to the prediction of the individual's future sickness absence behaviour using an auto-regressive model for annual frequencies is described elsewhere (Pocock, 1972).

\section{A cross-sectional study}

This section considers the 1964 sickness absence experience of all male manual workers born before 1945 who were continuously employed at the factory from mid-1963 to the end of 1964 (a total of 1263 men). Men with less than six months' service before 1964 are excluded so that all the sample were eligible for company sick-pay for the whole of 1964 and teenagers are excluded for they must necessarily be newly employed.

It is well known that sickness absence is related to age, and Taylor, Pocock, and Sergean (1972) have shown that shift workers tend to have less absence than day workers. Also long service employees tend to be older and the pattern of employment at the factory is such that a higher proportion of longservice employees are on shift work. It is essential to allow for these associations when considering the relationship between length of service and sickness absence, and this has been achieved by stratifying the above sample and using indirect standardization. Eight strata have been used, these being determined by the combination of four age groups (20-29, 30-39, 40-49, and 50-59 at the end of 1964) and two patterns of work (day-work and shift-work as on $\mathbf{3 1}$ December 1964). The need for such stratification is illustrated in Table 2 which shows the numbers of men and the average spells per man for each stratum.

Now, within each stratum men are divided into the four groups determined by their length of service at the beginning of 1964 , these being men with $\frac{1}{2}$ to 5,6 to 10,11 to 15 , and 16 or more years' service. Standardized sickness absence rates for these four groups are shown in Table 3 for the average spells and days per man and the percentage of persons with three or more spells.

It can be seen that the spells rate is lower for men with longer service with a $20 \%$ difference between the rates for men with $\frac{1}{2}$ to 5 and 16 or more years' service. However, for the days rate there appears to be no definite relationship with length of service. As both frequency (spells) and severity (days) are highly skewed in their distribution; it is difficult to apply formal tests of significance. For this reason

\section{TABLE 2}

Number of Men and Average Spells per Man of Sickness AbSENCE IN 1964 by Age AND Hours of Work (Total No. of MEN = 1 263)

\begin{tabular}{c|c|cccc}
\hline $\begin{array}{c}\text { Pattern } \\
\text { of work } \\
\text { on } \\
\begin{array}{c}31 \text { Dec. } \\
1964\end{array}\end{array}$ & \multicolumn{5}{|c}{ Age on 31 Dec. 1964 } \\
\cline { 2 - 6 } & & $20-$ & $30-$ & $40-$ & $50-59$ \\
\hline $\begin{array}{c}\text { Day } \\
\text { work }\end{array}$ & $\begin{array}{l}\text { No. of men } \\
\text { Spells/man }\end{array}$ & $\begin{array}{c}149 \\
2.03\end{array}$ & $\begin{array}{c}187 \\
1.60\end{array}$ & $\begin{array}{c}222 \\
1.26\end{array}$ & $\begin{array}{c}96 \\
0.88\end{array}$ \\
\hline $\begin{array}{c}\text { Shift } \\
\text { work }\end{array}$ & $\begin{array}{l}\text { No. of men } \\
\text { Spells/man }\end{array}$ & 94 & 181 & 197 & 137 \\
\hline
\end{tabular}




\section{TABLE 3}

Length of Service and Sickness AbSence in 1964 Average Spells and Days per Man and Percentage of Persons With 3 OR MORe Spells by Length of Service Standardized for Age and Pattern OF WORK

\begin{tabular}{|c|c|c|c|c|}
\hline $\begin{array}{l}\text { Length of } \\
\text { service }(y r)\end{array}$ & $\begin{array}{l}\text { No. of } \\
\text { men }\end{array}$ & $\begin{array}{l}\text { Spells/ } \\
\text { man }\end{array}$ & $\begin{array}{c}\text { Days/ } \\
\text { man }\end{array}$ & $\begin{array}{l}\% \text { Persons with } \\
3+\text { spells }\end{array}$ \\
\hline$\frac{1}{2}-5 \quad \ldots$ & 322 & 1.23 & $13 \cdot 7$ & $16.9\}_{1}$ \\
\hline 6-10 .. & 356 & $1 \cdot 14$ & $12 \cdot 0$ & $14 \cdot 4 \int^{1}$ \\
\hline $11-15$ & 233 & 1.07 & $11 \cdot 8$ & $\left.{ }^{12 \cdot 9}\right\}_{11 \cdot 3}$ \\
\hline 16 or more... & 352 & $1 \cdot 01$ & $12 \cdot 5$ & $10 \cdot 3\}^{11}$ \\
\hline
\end{tabular}

*Difference significant at $5 \%$ level (Cochran's test)

the percentage of persons with particular sickness absence characteristics (e.g., one or more spells, 14 or more days) has also been considered. As regards the frequency of sickness absence, the percentage of persons with three or more spells showed a marked relationship with length of service. Using Cochran's test, the difference in standardized percentages for those with 10 or less and 11 or more years of service was significant at the $5 \%$ level (n.d. $=2.56$ ). Thus, there is a tendency for the more recent employees to have repeated absence in a year. For the percentage of persons with one or more spells the trend with increased length of service was not formally significant. As regards the severity of sickness absence no trend with length of service was found to exist for the percentages of persons with 14 or more and 28 or more days of absence.

Though the above approach has allowed for age and hours of work, no allowance has been made for occupation or degree of responsibility. However, there is a limit to the number of factors which can be standardized for, and therefore in any cross-sectional study one can never hope to establish a firm relationship between sickness absence and length of service. This limitation must be remembered when interpreting the above results. The biggest jump in status is from hourly paid to staff, but the men studied here were all hourly paid. However, chargehands were included and they are usually drawn from employees with several years' service.

\section{Discussion}

The results presented in this paper are based on the experience of manual workers in one factory. Such a sample cannot be considered truly representative of all employees and industrial situations so that care should be exercised before drawing any general conclusions.

The marked rise in sickness absence rates once men become eligible for company sick-pay is in close agreement with the findings of Buzzard and Shaw (1952) and Denerley (1952), the difference here being that we are studying new employees and the sick-pay scheme is well established. It might be thought that because employees do not receive company sick-pay they may decide it is not worth while obtaining a medical certificate for any spell of absence in the first six months. This is extremely unlikely for men would still be eligible for National Insurance sickness benefit and also they are on trial in a new job, and absence for non-medical reasons would be undesirable. The dependence of absence behaviour on sick-pay arrangements should not be taken as clear evidence of malingering. It could be that employees simply could not afford to be 'off sick' without pay and as a consequence attended work in a state of ill-health. They may also be reluctant to jeopardize their continued employment. It would be interesting to do similar studies where the qualifying period of service for sick-pay was other than six months and the sick-pay scheme was less generous.

The results of the cross-sectional study show a slight fall in the spells rate with increased length of service while the days rate remains static. In order to explain this trend one must consider the characteristics of the long-service employee. $\mathrm{He}$ is a 'survivor' who has elected to stay in the same company and this indicates some degree of job satisfaction. $\mathrm{He}$ is also more likely to achieve higher status (e.g., chargehand) than the more recently employed and is therefore liable to have a greater degree of responsibility. All these factors are associated with lower sickness absence rates. However, it is possible that some long-service employees may feel 'trapped' by their pensions and are unable to leave, and in this circumstance sickness absence might increase. Thus, it seems plausible that length of service per se may have very little effect on sickness absence except as an indicator of job satisfaction and increased responsibility.

The prediction of an employee's future sickness absence liability at the end of one year's service obviously has limitations. Inaccuracies could be reduced by observing men for more than a year but men would then be more settled in the new environment and less amenable to attempts at changing their pattern of sickness absence. Thus, despite the higher degree of error involved an early assessment is perhaps of more practical value. However, the substantial probability of misclassification in predicting 'high' and 'low' absence groups means that such a procedure should not form the basis for any disciplinary action. 
This study is based on material included in a Ph.D. thesis at London University.

I am grateful to Dr. P. J. Taylor for his considerable advice throughout this investigation and also to Professor P. Armitage and Professor R. S. F. Schilling for their comments. I should like to thank the Company for the use of their sickness absence records.

\section{References}

Arbous, A. G., and Sichel, H. S. (1954). New techniques for the analysis of absenteeism data. Biometrika, 41, 77-90.

Buzzard, R. B., and Shaw, W. J. (1952). An analysis of absence under a scheme of paid sick leave. Brit. $J$. industr. Med., 9, 282-295.

Cooper, R., and Payne, R. (1965). Age and absence: a longitudinal study in three firms. Occup. Psychol., 39, 31-35.

Denerley, R. A. (1952). Some effects of paid sick leave on sickness absence. Brit. J. industr. Med., 9, 275-281.

Froggatt, P. (1970). Short-term absence from industry I. Brit. J. industr. Med., 27, 199-210.
Hazard, W. G. (1951). Putting absence records to use. Amer. J. publ. Hlth, 41, 1087-1095.

Hill, J. M. M., and Trist, E. L. (1955). Changes in accidents and other absences with length of service. Hum. Relat., 8, 121-152.

Newbold, E. M. (1927). Practical applications of the statistics of repeated events, particularly to industrial accidents. J. roy. statist. Soc., 90, 487-547.

Pocock, S. J. (1972). Chapter 6 of Statistical Studies of Sickness Absence with Special Reference to Temporal Variation. Ph.D. thesis, London University.

Taylor, P. J. (1967). Individual variations in sickness absence. Brit. J. industr. Med., 24, 169-177.

, Pocock, S. J., and Sergean, R. (1972). Absenteeism of shift and day workers. Brit. J. industr. Med., 29, 208-213.

Wyatt, S. (1945). A study of certified sickness absence among women in industry. Rep. industr. Hlth Res. Bd., No. 86, London.

Received for publication April 5, 1972. 